\title{
An Interview with Anne O'Keeffe
}

Senior Lecturer in Applied Linguistics \& English Language Teaching Dept. of English Language and Literature, Mary Immaculate College Coordinator of the Inter-Varietal Applied Corpus Studies Research Centre

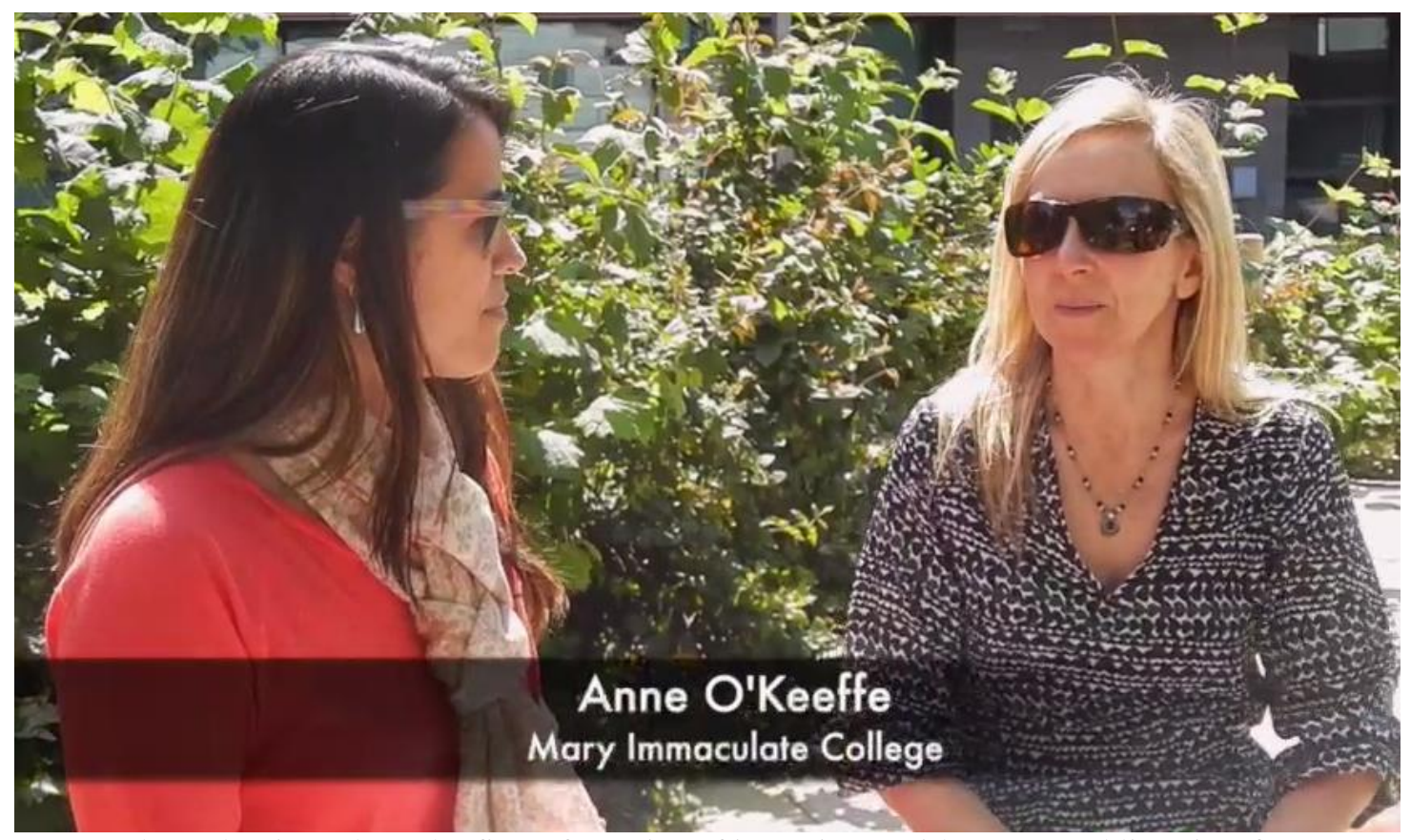

We are pleased to introduce the first of a series of interviews with renowned linguists from around the world who bring their international expertise and experience within the scope of the theme of the respective edition. In the current edition, we gratefully present a discussion with Professor Anne O'Keeffe, senior lecturer at Mary Immaculate College at the University of Limerick and director of the Inter-Varietal Applied Corpus Studies (IVACS) Research Center. Professor O'Keeffe was kind enough to meet with us at the IVACS Conference at Newcastle University (UK) this year to talk about recent trends in research in the area of pragmatics and the importance of pragmatics in the language learning classroom.

We would like to compliment Professor O'Keeffe for her special contribution to this edition. We hope you will enjoy watching the interview and that, through its contents, further debates can be encouraged in the area of pragmatics and teaching. Please find below the link to the interview and a list of the questions that guided the interview.

http://ebooks.pucrs.br/edipucrs/periodicos/belt/okeeffe.mov

1. What is the importance of Pragmatics for language teaching and language learning? How does Corpus Linguistics contribute to these processes?

2. Many language teachers have no background in linguistics. Is it possible for them to apply results from linguistic research in the classroom?

3. Corpus Linguistics has been increasingly used in Applied Linguistics studies. What are some benefits and challenges of using Corpus Linguistics in researching Pragmatics, as opposed to other perspectives?

4. Could you tell us about some of the research projects being carried out at the IVACS (Inter-Varietal Applied Corpus Studies) Research Centre? What are some future trends developing in the areas of Pragmatics, Corpus Linguistics and Language Teaching?

5. What are some books or papers you can suggest for Pragmatics researchers who want to learn more about Corpus Linguistics and Language Teaching? 